\title{
Administration of Daratumumab in the Case of Severe Pure Red Cell Aplasia after Allogeneic Transplantation
}

\section{Bicsko RR*, Magyari F, Szasz R, Illes A and} Gergely L

Department of Haematology, University of Debrecen, Hungary

*Corresponding author: Bicsko RR, Department of Hematology, University of Debrecen, 4032 Debrecen Nagyerdei krt 98, Hungary

Received: J anuary 25, 2021; Accepted: February 26, 2021; Published: March 05, 2021

\begin{abstract}
Pure red cell aplasia is a well-known complication of $\mathrm{ABO}$ major mismatched allogeneic hematopoietic stem cell transplantation. This side effect can be selflimiting, but is occasionally persistent and treated using modalities such as steroids, anti-thymocyte globulin, erythropoietin, donor lymphocyte infusions, rituximab, or plasmapheresis. In some cases, these standard treatments have no effect. We describe a patient with pure red cell aplasia, who received an ABO major mismatched allogeneic hematopoietic stem cell transplantation. $\mathrm{He}$ underwent various treatment for the pure red cell aplasia, but no reticulocytes were present. Daratumumab was started on day 60 and 69 after transplantation, and after two doses of daratumumab, reticulocytosis and the hematocrit increased. Our case clearly represents an additional successful administration of daratumumab, resulting in full recovery of the patient with pure red cell aplasia.
\end{abstract}

Keywords: Allogeneic transplant, pure red cell aplasia, daratumumab, ABO mismatch

\section{Abbreviations \\ PRCA: Pure Red Cell Aplasia \\ Case Presentation}

Pure red cell aplasia is a syndrome characterized by a severe normocytic and normochromic anaemia, reticulocytopenia, and absence of erythroblasts from an otherwise normal bone marrow $[1,2]$. It can be congenital, but mostly associated with other diseases, such as malignancies, autoimmune disorders, parvovirus B19 infections, drugs or toxic agents [3,4]. Pure red cell aplasia is a well-known complication after major $\mathrm{AB} 0$ mismatched allogeneic hematopoietic stem cell transplantation. It is more common in group 0 recipients with group $\mathrm{A}$ donors, and based on the presence of residual recipient $B$ lymphocytes or plasma cells, which can produce isohemagglutinins against donor red blood cells. The laboratory findings are the following: The absolute reticulocyte count is always less than $10000 /$ millilitre (reticulocyte percentage, $1 \%$ ), and in many cases is much lower. In most of the cases white blood cell and platelet counts are normal. The diagnosis of PRCA requires the detection of the antibodies in the sera of patients upon the abovementioned anaemia and low reticulocyte count [5]. The occurrence of PRCA after a major mismatch allogenic transplantation severely impacts the patients quality of life, as transfusion support may be needed up to 6 months [6].

The treatment of PRCA is usually based on immunosuppression, there are many different agents such as steroids, antithymocyte globulin, erythropoietin, donor lymphocyte infusions, rituximab, or plasmapheresis. But in some cases, these standard treatments have no effect, and the time to recovery is relatively slow [7]. As the pathogenetic base of the condition is residual plasma cells, it is logical to target these to stop production of the antibodies. CD38 as expressed on activated B cells and plasma cells, posing a very rational target for therapy. It is also expressed on activated T cells, helping the $\mathrm{B}$ cell antibody production [8]. Daratumumab is a humanized antiCD38 monoclonal antibody developed for the treatment of myeloma multiplex. It is a rational approach to utilize daratumumab to target, and eliminate the resting plasma cells from the donor in case of developed PRCA. This treatment has been recently published as case reports $[9,10]$. Here we describe a case of post allogenic transplant PRCA, where a short course of daratumumab therapy yielded fast and complete resolution of PRCA without any side effects.

A 66-year-old man with acute myeloid leukemia presented for evaluation. Given the refracter disease, allogeneic stem cell transplantation was planned. During the donor search, he received two cycles of FLAG-IDA (fludarabine, cytarabine, idarubicin and granulocyte colony stimulating factor), and two cycles of high-dose cytarabine. From day -9 to day -1 patient received a reduced intensity conditioning regimen consisting of fludarabin (200 milligrams), busulfan (540 milligrams), thymoglobulin (400 milligrams). An $11 / 12$ DP mismatched, unrelated donor was identified with a major $\mathrm{ABO}$ incompatibility. His pretransplant blood type was 0 positive, and he was transplanted from an A positive bone marrow donor. For prophylaxis against graft versus host disease, the standard cyclosporin, methotrexate and mycophenolate mofetil was given.

On the day of transplantation, our patient received a stem cell transplant with a dose of $5.31 \times 10^{6} \mathrm{CD} 34^{+}$stem cells per body weight kilogram. Engraftment of white blood cells developed on day 24, and platelet count started to increase on day 19, but the patient continued to have anaemia, and required red blood cell transfusions. With short tandem repeat analysis on day 30 after transplant, the donor was responsible for $93 \%$ of haematopoiesis. Red blood cells with A blood group were not present. After six weeks of stem cell transplantation, a control bone marrow biopsy was done, and showed no blasts, and no sing of acute myeloid leukemia, but a serious red cell aplasia with 


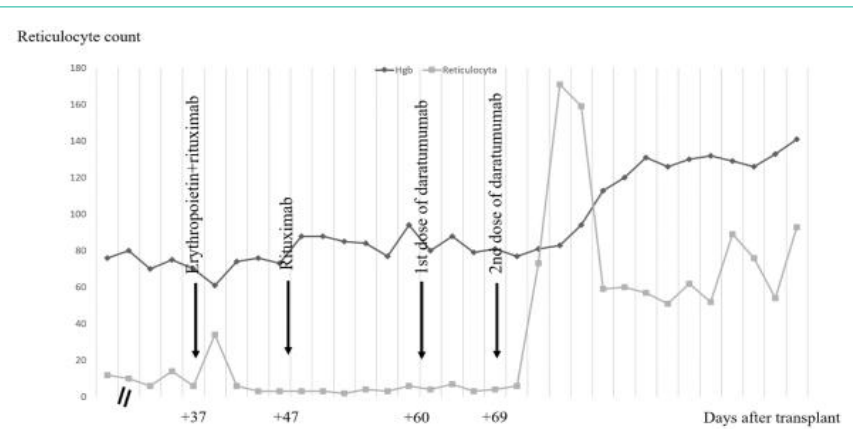

Figure 1: The absolute reticulocyte count and hemoglobin levels are presented during the timeline. Hemoglobin is presented as grams per liter value and reticulocyte as giga per liter. The administration of Rituximab, erythropoetin alpha and daratumumab is indicated by arrows on the stated days after transplantation. Rituximab and erythropoetin alpha were not benificial. Patient received 400 milligrams of daratumumab intravenously four times on day $60,69,78$ and 96 after stem cell transplantation. Thereafter hemoglobin level stabilized, and the reticulocyte count is increased.

3-4 \% of erythroid elements, and normoblasts were missing. Anti-A antibody titer was $1: 64$ on day 28 , day 44 and day 54 too. To treat PRCA, he received $100 \mathrm{mg}$ of rituximab on day 37 and 47 , but it had no effect on the hematocrit level. Alfa-epoetin was administered three times, on day 27,37 , and 47 , but the hematocrit and reticulocyte count did not increase. Patient received 400 milligrams of daratumumab intravenously on day 60, 69, 78 and 96 after stem cell transplantation. After this treatment the hemoglobin level stabilized, and we could detect an increase in the reticulocyte count (Figure 1). This was followed by a decrease of the anti-A titer. He did not require any red blood cell transfusion from day 75 .

\section{Discussion and Conclusions}

Our patient received a 11/12 (1 DP mismatch) bone marrow with a major AB0 mismatch after which he developed a characteristic PRCA [11,12], requireing red blood cell supplementation besides stable neutrophil and thrombocyte levels. Steroids, erythropoetin alpha and rituximab administration did not improve the situation, thus we administered intravenously daratumumab 4 times. This treatment resulted in a complete recovery and rise in circulating red cells. It is known that recipient plasma cells producing antibodies may persist after conditioning during allogenic transplantation. This results in prolonged PRCA in case of major $\mathrm{AB} 0$ mismatch. This situation is sometimes difficult to treat and may persist for up to a year after the transplantation. The therapy of this condition is quite challenging. Recently the anti-CD38 monoclonal antibody, daratumumab was published to be beneficial in this situation [9]. Our case clearly represents an additional successful administration of daratumumab, resulting in full recovery of the patient. We did not encounter any side effects, no signs of graft versus host disease were present. The patient had a stable full donor chimerism by day 100 , with steady neutrophil and platelet levels.

\section{References}

1. Worel N. ABO-Mismatched Allogeneic Hematopoietic Stem Cell Transplantation. Transfus Med Hemother. 2016; 43: 3-12.

2. Quek J, Lee J, Lim LF, Diong C, Goh YT, Gopalakrishnan S, et al. Donor-type fresh frozen plasma is effective in preventing hemolytic reaction in major $A B O$ incompatible allogeneic stem cell transplant. Transfusion. 2019; 59: 335-339.

3. Vaezi M, Oulad Dameshghi D, Souri M, Setarehdan SA, Alimoghaddam K, Ghavamzadeh A. ABO Incompatibility and Hematopoietic Stem Cell Transplantation Outcomes. Int J Hematol Oncol Stem Cell Res. 2017; 11: 139-147.

4. Means RT. Pure red cell aplasia. Blood. 2016; 128: 2504-2509.

5. Sawada K, Fujishima N, Hirokawa M. Acquired pure red cell aplasia: updated review of treatment. Br J Haematol. 2008; 142: 505-514.

6. Tomac G, Bojanic I, Mazic S, Vidovic I, Raos M, Cepulic BG, et al. Haemolysis, pure red cell aplasia and red cell antibody formation associated with major and bidirectional $\mathrm{ABO}$ incompatible haematopoietic stem cell transplantation. Blood Transfus. 2018; 16: 397-404.

7. Barcellini W, Fattizzo B, Zaninoni A. Management of refractory autoimmune hemolytic anemia after allogeneic hematopoietic stem cell transplantation: current perspectives. J Blood Med. 2019; 10: 265-278.

8. van de Donk NWCJ. Immunomodulatory effects of CD38-targeting antibodies. Immunol Lett. 2018; 199: 16-22.

9. Chapuy Cl, Kaufman RM, Alyea EP, Connors JM. Daratumumab for Delayed Red-Cell Engraftment after Allogeneic Transplantation. N Engl J Med. 2018; 379: 1846-1850.

10. Salas MQ, Alahmari A, Lipton JH. Successful treatment of refractory red cell aplasia after allogeneic hematopoietic cell transplantation with daratumumab. Eur J Haematol. 2020.

11. Bathini S, Holtzman NG, Koka R, Singh Z, Wildind E, Zou Y, et al. Refractory postallogeneic stem cell transplant pure red cell aplasia in remission after treatment with daratumumab. Am J Hematol. 2019; 94: E216-E219.

12. Even-Or E, Naser Eddin A, Shadur B, Schejter YD, Najajreh M, Zelig O, et al. Successful treatment with daratumumab for post-HSCT refractory hemolytic anemia. Pediatr Blood Cancer. 2019: e28010. 